\title{
Política de segurança alimentar e nutricional no Brasil: uma análise da alocação de recursos
}

\author{
Marta Battaglia Custódio, ${ }^{1}$ Tânia Yuka Yuba ${ }^{1}$ e Denise Cavallini Cyrillo
}

Como citar Custódio MB, Yuba TY, Cyrillo DC. Política de segurança alimentar e nutricional no Brasil: uma análise da alocação de recursos. Rev Panam Salud Publica. 2013;33(2):144-50.

RESUMO Objetivo. Descrever a evolução e a distribuição dos recursos da União para programas e ações que se inserem nas diretrizes brasileiras da Política Nacional de Segurança Alimentar e Nutricional (PNSAN) no período de 2004 a 2010.

Métodos. Este estudo descritivo utilizou dados do Portal da Transparência mantido pela Controladoria Geral da União, que gera planilhas de Excel para cada pesquisa realizada. Para o levantamento dos recursos alocados, foi organizada uma base de dados contendo todas as ações executadas pelo governo federal entre 2004 e 2010. Essa base foi revisada e as ações que não eram relativas à PNSAN foram descartadas. Os montantes anuais obtidos tiveram os valores corrigidos pelo Índice de Preços ao Consumidor e atualizados para o ano de 2010. Como as ações são parte de programas específicos, a soma dos recursos destinados a todas as ações de um programa equivaleu aos recursos destinados ao programa como um todo. Os programas foram então hierarquizados de acordo com o volume de recursos recebidos em 2010.

Resultados. Das 5014 ações que receberam recursos da União no período, 814 foram relacionadas à PNSAN (229 programas). Houve crescimento dos recursos alocados para os programas da PNSAN, alcançando, em 2010, US\$ 15 bilhões (82\% superior ao gasto no ano de 2004). A maior proporção dos recursos foi absorvida pelo Programa Bolsa Familia. Dez programas receberam $90 \%$ dos recursos, sendo cinco ligados aos processos de produção alimentar. Conclusões. A PNSAN vem recebendo aporte crescente de recursos concentrados em ações e programas que favorecem a segurança alimentar e nutricional.

Palavras-chave

Alocação de recursos; política de nutrição e alimentação; segurança alimentar e nutricional; política social; Brasil.

O Brasil tem longa experiência na execução de programas sociais voltados para a questão alimentar e nutricional (1). O mais antigo em funcionamento, o Programa Nacional de Alimentação Escolar (PNAE), originou-se em 1954

\footnotetext{
1 Universidade de São Paulo, Programa de Pósgraduação Interunidades em Nutrição Humana Aplicada (PRONUT), São Paulo (SP), Brasil. Correspondência: Maria Battaglia Custódio, martacustodio@ hotmail.com, marta.custodio@mds.gov.br

2 Universidade de São Paulo, Faculdade de Economia, Administração e Contabilidade (FEA), São Paulo (SP), Brasil.
}

(2). Na década de 1970, surgiram o Programa Nacional de Alimentação e Nutrição (PRONAN) e o Programa de Alimentação do Trabalhador (PAT) (3). Além desses, muitos outros foram executados temporariamente ou de forma desarticulada, sem caracterizar uma política pública coerente e sistemática. Nos últimos anos, entretanto, o Brasil vem tendo sucesso em consolidar sua Política Nacional de Segurança Alimentar e Nutricional (PNSAN) de forma institucionalizada, com caráter estatal, ao invés de ser vinculada apenas a um governo específico.

A lei federal 11346 (4), conhecida como Lei Orgânica de Segurança Alimentar e Nutricional (LOSAN), criou o Sistema Nacional de Segurança Alimentar e Nutricional (SISAN) no Brasil. Em 2010, a emenda constitucional 64 introduziu a alimentação como um direito social na constituição federal, um marco na conquista pelo direito humano à alimentação. No mesmo ano em que o direito humano à alimentação ganhou 
status constitucional, a LOSAN foi regulamentada, por meio do decreto 7272 . Tais instrumentos legais integram o conjunto de regras de ordenamento jurídico do país, que visam a garantir uma alimentação saudável e adequada a todos os brasileiros, em consonância com as diretrizes voluntárias (5) da Organização das Nações Unidas para a Agricultura e Alimentação (FAO) e com os tratados internacionais de direitos humanos, dos quais o Brasil é signatário.

O SISAN visa a proporcionar a garantia do direito humano à alimentação e considera que a segurança alimentar e nutricional abrange acesso aos alimentos, sustentabilidade ambiental, promoção da saúde, qualidade e diversidade cultural e estímulo a uma economia solidária. O sistema parte do princípio de que o acesso aos alimentos deve ser universal e baseado em práticas que respeitem a dignidade das pessoas, com participação social na condução da política, em todas as suas etapas $(4,6)$.

Diante desse cenário, o presente trabalho tem por objetivo descrever a evolução e a distribuição dos recursos da União para os programas e ações de segurança alimentar e nutricional que, juntamente com instrumentos legais, compuseram a PNSAN no período de 2004 a 2010.

\section{MÉTODOS}

Este estudo descritivo foi baseado em dados secundários oficiais e em uma pesquisa documental. Para se chegar ao total alocado pelo governo federal para a PNSAN, foi considerada a execução orçamentária da União, cuja despesa é classificada de acordo com ações e programas (7) que organizam a atividade dos entes federados para a realização conjunta dos objetivos estratégicos definidos no plano plurianual federal para um período de 4 anos (8). A fonte dos dados foi o Portal da Transparência, uma ferramenta de controle social mantida pela Controladoria Geral da União (CGU), que desde 2004 disponibiliza na Internet a execução financeira do governo federal brasileiro (9).

Inicialmente, foi necessário determinar quais ações governamentais estavam associadas à PNSAN, uma vez que esta é desenvolvida por vários órgãos e que não há uma lista oficial de ações e programas que a compõem. Para isso, utilizaram-se como critérios os elemen- tos do conceito de segurança alimentar e nutricional adotado pelo CONSEA (6) e que estão no texto da LOSAN (4). Portanto, foram selecionadas ações governamentais relacionadas à cadeia produtiva (produção, abastecimento, comercialização) e ao consumo de alimentos, ações relativas à saúde e ao respeito aos hábitos culturais, na medida em que esses hábitos compõem a identidade do grupo social (10), e ações relativas à sustentabilidade ambiental, social e econômica. Como a legislação exige que o nome de cada ação que integra um programa seja o mais claro possível, expressando em linguagem clara o seu objeto (8), os nomes das ações eram relacionados aos programas e à saúde nutricional e alimentar, o que permitiu identificar com razoável precisão todas as ações da PNSAN.

Além dos critérios mencionados, foram considerados os elementos do monitoramento e do controle social contidos no texto do Projeto Fome Zero (11) e na LOSAN como princípios básicos do SISAN. Assim, os recursos destinados ao funcionamento do Conselho de Segurança Alimentar e Nutricional, das Conferências e outros também foram considerados na composição dos recursos destinados à PNSAN.

Uma vez identificadas as ações da PNSAN, foi feito o levantamento do montante dos recursos alocados pela União para essas ações durante os anos de 2004 a 2010. Como todas as ações governamentais são atreladas a um programa de governo (8), a soma dos montantes alocados para cada ação permite identificar os programas que receberam a maior proporção dos recursos destinados à PNSAN em cada ano do período analisado.

Para o levantamento dos recursos alocados, foi organizada uma base de dados contendo todas as ações executadas pelo governo federal entre 2004 e 2010, obtidas mediante consulta ao Portal da Transparência, que gera planilhas de Excel para cada pesquisa realizada. A base de dados foi revisada e as ações que não eram relativas à PNSAN foram descartadas (como as ações relacionadas ao agronegócio exportador e à gestão e administração dos programas).

As informações do Portal da Transparência são disponibilizadas segundo ano, ações e programas conforme duas categorias: a primeira mostra os recursos públicos federais transferidos pela União para as unidades federativas e a segunda mostra os recursos que foram gastos diretamente pelo governo federal nos programas.

Os dados sobre os recursos transferidos são classificados segundo função (por exemplo, "agricultura"), subfunção (por exemplo, "abastecimento", como subfunção de "agricultura"), unidade federada que recebeu o recurso, programa e ação. Com relação aos recursos aplicados diretamente pela União, as informações estão disponibilizadas nas seguintes categorias: órgão superior (presidência e ministérios), órgão subordinado (órgãos da administração direta e indireta vinculados aos órgãos superiores), unidade gestora (vinculada ao órgão subordinado), grupo, função, subfunção, programa e ação.

Como fica evidente, a forma como a informação é disponibilizada, tanto referente aos recursos transferidos quanto aos aplicados diretamente, permite a associação entre a ação e o programa. Como é possível que uma ação de governo tenha parte do recurso orçamentário gasta diretamente e outra parte transferida, ao se proceder à agregação dos montantes identifica-se o valor efetivamente gasto pelo governo federal com a segurança alimentar e nutricional em cada programa.

Os montantes anuais obtidos a partir da pesquisa tiveram os valores correntes corrigidos pelo Índice de Preços ao Consumidor Amplo (IPCA), a preços de 2010. Os programas foram então hierarquizados de acordo com o volume de recursos recebidos em 2010 .

\section{RESULTADOS}

Das 5014 ações que receberam recursos da União de 2004 a 2010, 814 foram relacionadas à PNSAN. Agregadas, foram associadas a 229 diferentes programas do governo federal, executados por 22 ministérios, sobretudo pelos ministérios do Desenvolvimento Social e Combate à Fome, da Educação e Cultura, da Agricultura, Pecuária e Abastecimento e do Desenvolvimento Agrário. A evolução do montante global dos recursos da política, segundo tipo de alocação (aplicação direta ou transferência), no referido período, é apresentada na tabela 1 . Os valores apresentados, originalmente em reais (a preço de 2010), foram convertidos para dólares americanos segundo cotação em 31 de dezembro de 2010 (12). 
Observa-se que foram alocados para a PNSAN, no ano de 2010, cerca de US\$ 15 bilhões, o que representou US\$ 78,66 per capita, considerando a população brasileira de 190,7 milhões de habitantes (13). Esse montante equivaleu a 1,96\% do total de gastos do governo federal com programas de todas as áreas, de acordo com as informações do Portal da Transparência, e foi $82 \%$ superior ao gasto no ano de 2004, em termos reais. Apesar das oscilações, os recursos cresceram em termos reais à taxa média de $10,5 \%$ ao ano (figura 1 ).

A tabela 1 mostra também os gastos realizados diretamente e o montante transferido para estados, Distrito Federal e municípios. Verifica-se que a maior proporção dos recursos foi destinada por meio de transferências, com variação de $76,4 \%$ (2009) a $86,9 \%$ (2008) do total alocado. Observa-se ainda uma tendência declinante da proporção dos recursos aplicados diretamente (figura 2), com um ano atípico em 2009, quando a proporção das despesas diretas foi a maior do período (23,6\%). O ano de 2008 também foi atípico, na medida em que as aplicações diretas do governo federal reduziram-se em quase $40 \%$ em relação ao ano anterior, representando apenas $13,1 \%$ do montante destinado à PNSAN naquele ano. Como adiante demonstrado, mais de $60 \%$ dos recursos transferidos nesse ano foram aplicados em um único programa.

A distribuição dos recursos segundo programas, em termos absolutos e proporcionais, está apresentada na tabela 2. Do volume total de recursos destinados aos 229 programas identificados, mais de $90 \%$ foram destinados a apenas 10 programas em 2010, sendo o Programa Bolsa Família (PBF) responsável isoladamente por $58,5 \%$ do total nesse ano.

O exame da evolução dos recursos aplicados nesses programas revela algumas oscilações que merecem destaque. Observa-se que o PBF, um programa de transferência de renda com condicionalidades para famílias pobres, absorveu mais de $50 \%$ dos recursos da PNSAN em todos os anos analisados, sendo a menor participação em 2006 (52,2\%) e a maior em $2008(61,7 \%)$, como se pode verificar na tabela 2 .

O segundo programa que se destaca é o Programa Nacional de Alimentação Escolar, no âmbito do Brasil Escolarizado (que contempla diversas ações visando ao acesso e à permanência de
TABELA 1. Recursos alocados pela União para ações de segurança alimentar e nutricional segundo tipo de alocação, Brasil, 2004 a 2010a

\begin{tabular}{|c|c|c|c|c|c|}
\hline \multirow[b]{3}{*}{ Ano } & \multicolumn{2}{|c|}{ Tipo de alocação } & \multirow{3}{*}{ Total } & \multirow{3}{*}{$\begin{array}{l}\text { Variação sobre } \\
\text { ano anterior (\%) }\end{array}$} & \multirow[b]{3}{*}{ Índice (base 2004) } \\
\hline & Direta & Transferência & & & \\
\hline & \multicolumn{2}{|r|}{ Milhões de dólares } & & & \\
\hline 2004 & 1836,63 & 6418,35 & 8254,99 & & 100,0 \\
\hline 2005 & 2174,23 & 7527,99 & 9702,23 & 17,5 & 118,0 \\
\hline 2006 & 2211,01 & 8923,12 & 11134,13 & 14,8 & 135,0 \\
\hline 2007 & 2452,97 & 9 409,99 & 11862,96 & 6,5 & 143,7 \\
\hline 2008 & 1562,77 & 10340,50 & 11903,27 & 0,3 & 144,2 \\
\hline 2009 & 3370,78 & 10927,15 & 14297,93 & 20,1 & 173,2 \\
\hline 2010 & 2822,46 & 12199,59 & 15022,05 & 5,1 & 182,0 \\
\hline
\end{tabular}

a Valores para 2010 convertidos para dólar americano segundo cotação do Banco Central do Brasil em 31 de dezembro de 2010 (US\$1,00 = R \$ 1,6658) (12).

FIGURA 1. Recursos alocados pela União para a Política Nacional de Segurança Alimentar e Nutricional, Brasil, 2004 a 2010

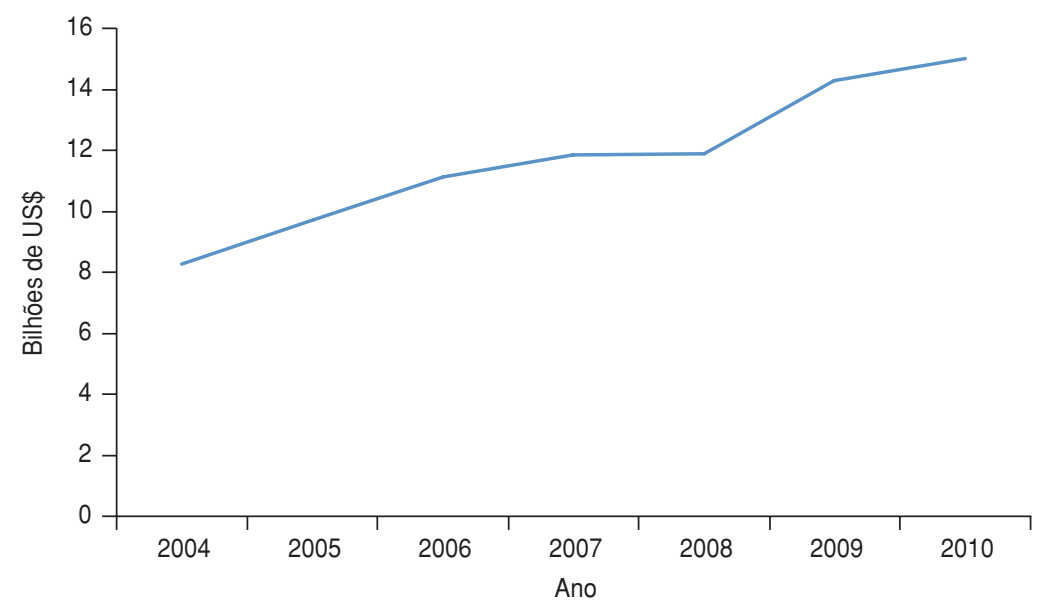

a Em bilhões de dólares (valores de 2010).

FIGURA 2. Proporção de recursos aplicados diretamente pela União em ações de segurança alimentar e nutricional em relação ao total de recurso destinado à Política Nacional de Segurança Alimentar e Nutricional, Brasil, 2004 a 2010a

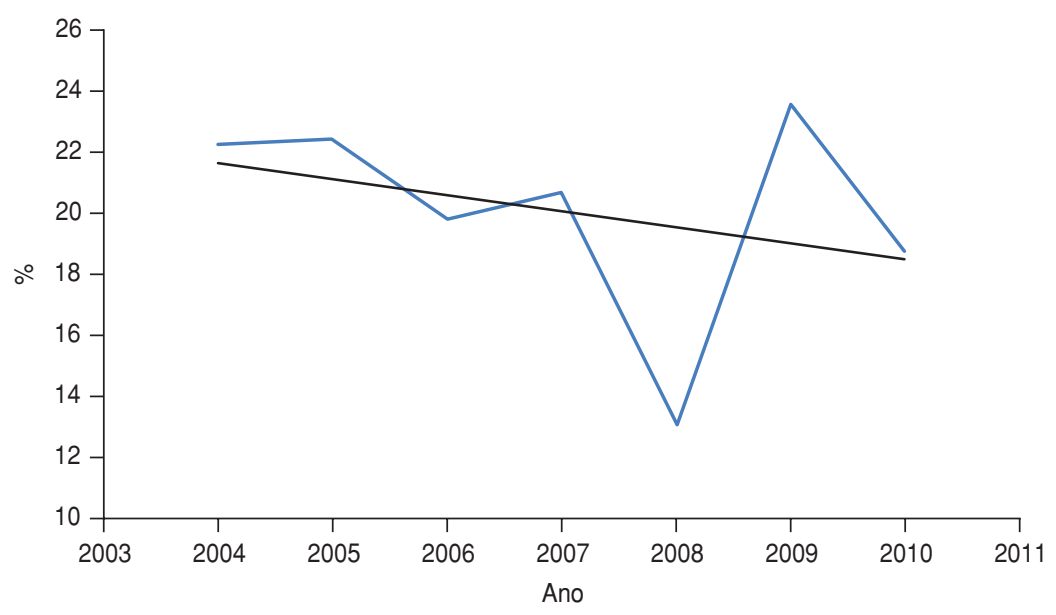

a A linha preta equivale à curva de tendência. 
TABELA 2. Distribuição dos recursos da Política Nacional de Segurança Alimentar e Nutricional segundo programas hierarquizados de acordo com o aporte em 2010, Brasil, 2004 a 2010a

\begin{tabular}{|c|c|c|c|c|c|c|c|c|c|c|c|c|c|c|}
\hline \multirow[b]{2}{*}{ Programa } & \multicolumn{2}{|c|}{2004} & \multicolumn{2}{|c|}{2005} & \multicolumn{2}{|c|}{2006} & \multicolumn{2}{|l|}{2007} & \multicolumn{2}{|c|}{2008} & \multicolumn{2}{|c|}{2009} & \multicolumn{2}{|c|}{2010} \\
\hline & $\begin{array}{l}\text { US\$ } \\
\text { milhões }\end{array}$ & $\%$ & $\begin{array}{l}\text { US\$ } \\
\text { milhões }\end{array}$ & $\%$ & $\begin{array}{l}\text { US\$ } \\
\text { milhões }\end{array}$ & $\%$ & $\begin{array}{l}\text { US\$ } \\
\text { milhões }\end{array}$ & $\%$ & $\begin{array}{l}\text { US\$ } \\
\text { milhões }\end{array}$ & $\%$ & $\begin{array}{l}\text { US\$ } \\
\text { milhões }\end{array}$ & $\%$ & $\begin{array}{l}\text { US\$ } \\
\text { milhões }\end{array}$ & $\%$ \\
\hline \multicolumn{15}{|l|}{ Programa Bolsa } \\
\hline Família (PBF) & 4610,52 & 56,0 & 5188,22 & 53,5 & 5806,96 & 52,2 & 6397,77 & 53,9 & 7344,93 & 61,7 & 7924,90 & 55,4 & 8788,14 & 58,5 \\
\hline $\begin{array}{l}\text { Programa Nacional de } \\
\text { Alimentação Escolar }\end{array}$ & & & & & & & & & & & & & & \\
\hline $\begin{array}{l}\text { (PNAE) } \\
\text { Recursos Pesqueiros }\end{array}$ & 823,18 & 10,0 & 925,56 & 9,5 & 1056,12 & 9,5 & 1053,04 & 8,9 & 988,83 & 8,3 & 1259,62 & 8,8 & 1822,39 & 12,1 \\
\hline $\begin{array}{l}\text { Sustentáveis } \\
\text { (PRPS) }\end{array}$ & 7,82 & 0,1 & 3,33 & 0,0 & 5,17 & 0,0 & 15,92 & 0,1 & 5,34 & 0,0 & 595,82 & 4,2 & 712,77 & 4,7 \\
\hline $\begin{array}{l}\text { Acesso à Alimentação } \\
\text { (AAL) }\end{array}$ & 125,12 & 1,5 & 90,87 & 0,9 & 385,36 & 3,5 & 380,31 & 3,2 & 399,03 & 3,4 & 475,81 & 3,3 & 608.88 & 4.1 \\
\hline Agricultura Familiar & & & & & & & & & & & & & & \\
\hline $\begin{array}{c}(\mathrm{AF}) \\
\text { Abastecimento }\end{array}$ & 79,22 & 1,0 & 143,68 & 1,5 & 174,37 & 1,6 & 234,75 & 2,0 & 519,96 & 4,4 & 1034,85 & 7,2 & 543,22 & 3,6 \\
\hline Agroalimentar (AAG) & 523,25 & 6,4 & 1086,77 & 11,2 & 653,49 & 5,9 & 499,1 & 4,2 & 65,86 & 0,6 & 529,61 & 3,7 & 430,38 & 2,9 \\
\hline $\begin{array}{l}\text { Urbanização, } \\
\text { Regularização } \\
\text { Fundiária e } \\
\text { Integração de } \\
\text { Assentamentos }\end{array}$ & & & & & & & & & & & & & & \\
\hline $\begin{array}{l}\text { Precários (URFIAP) } \\
\text { Proteção e Promoção } \\
\text { dos Povos }\end{array}$ & 2,58 & 0,0 & 9,71 & 0,1 & 7,98 & 0,1 & 7,12 & 0,1 & 469,77 & 3,9 & 411,02 & 2,9 & 356,89 & 2,4 \\
\hline Indígenas (PPPI) & 11,57 & 0,1 & 15,07 & 0,2 & 12,39 & 0,1 & 6,81 & 0,1 & 160,97 & 1,4 & 200,06 & 1,4 & 203 & 1,4 \\
\hline $\begin{array}{l}\text { Apoio ao } \\
\text { Desenvolvimento do } \\
\text { Setor Agropecuário }\end{array}$ & & & & & & & & & & & & & & \\
\hline $\begin{array}{l}\text { (ADSP) } \\
\text { Desenvolvimento da }\end{array}$ & 48,79 & 0,6 & 44,81 & 0,5 & 101,98 & 0,9 & 131,67 & 1,1 & 175,64 & 1,5 & 230,64 & 1,6 & 151,31 & 1,0 \\
\hline $\begin{array}{l}\text { Desenvolvimento da } \\
\text { Agricultura Irrigada } \\
\text { (DAl) }\end{array}$ & 127,42 & 1.5 & 77,66 & 0.8 & 56.7 & 0.5 & 89.41 & 0.8 & 78.71 & 07 & 178.41 & 12 & 13621 & 9 \\
\hline Outros (219 & & & & & & & & & & & & & & \\
\hline programas) & 1877,87 & 22,8 & 2116,50 & 21,8 & 2873,62 & 25,8 & 3047,06 & 25,7 & 1694,24 & 14,2 & 1457,19 & 10,2 & 1268,84 & 8,4 \\
\hline Total & 8237,33 & 100,0 & 9702,19 & 100,0 & 11134,13 & 100,0 & 11862,96 & 100,0 & 11903,27 & 100,0 & 14297,93 & 100,0 & 15022,05 & 100,0 \\
\hline
\end{tabular}

a Valores de 2010. Nas colunas, o valor percentual se refere ao total do ano.

crianças, adolescentes, jovens e adultos na educação básica), com $12,1 \%$ do total de recursos alocados em 2010 e participação variando entre $8,3 \%$ (2008) e 10,0\% (2004). De fato, esse programa enfrentou oscilações expressivas, principalmente nos anos de 2007 e 2008; no entanto, os recursos recebidos nos dois últimos anos do período implicaram um aumento de $121 \%$ em relação ao valor de 2004.

De acordo com a distribuição dos recursos em 2010, o Programa Recursos Pesqueiros Sustentáveis aparece na terceira posição, tendo recebido $4,7 \%$ do total de recursos da PNSAN. O quarto programa em aporte de recursos foi o Acesso à Alimentação, que engloba diversas ações para ampliar o acesso aos alimentos, como instalação de bancos de alimentos, restaurantes populares, hortas e cozinhas comunitárias, aquisição de alimentos da agricultura familiar, instalação de cisternas, agricultura urbana.
Considerando a alocação de 2010, dos 10 principais programas que compõem a PNSAN, os quatro primeiros são voltados para o consumo e o acesso à alimentação. Dos outros seis, cinco - a exceção é o programa de Proteção e Promoção dos Povos Indígenas - são relacionados à produção, tendo recebido 9,4\% do total dos recursos de 2010. Desses dois se destacam, em importância, o Programa de Agricultura Familiar, que saltou de aproximadamente US\$ 79 milhões, em 2004, para quase US\$ 543 milhões, em 2010, com um pico de US\$ 1 bilhão em 2009, e o Programa Urbanização, Regularização Fundiária e Integração de Assentamentos Precários, que recebeu US\$ 469 milhões da União em 2008. Cabe lembrar que a posse e a titulação da terra é um dos principais entraves à produção da agricultura familiar, que, por sua vez, é a principal fornecedora de alimentos que compõem a dieta dos brasileiros (14).

\section{DISCUSSÃO}

O montante de recursos públicos destinados às ações que visam à segurança alimentar e nutricional e que compõem a PNSAN apresentou tendência crescente no período de 2004 a 2010, confirmando as prerrogativas legais (sanção da LOSAN, em 2006; inclusão do direito humano à alimentação na constituição federal, em 2010; e aprovação de leis similares nos estados e municípios) que elegeram a PNSAN como uma política de Estado e não meramente de um governo (15), como se caracterizavam, tradicionalmente, os programas e ações de nutrição e alimentação no Brasil.

Nos dois anos seguintes à aprovação da LOSAN (2007 e 2008), a taxa de crescimento do volume de recursos destinados à PNSAN foi menor; entretanto, os recursos em termos reais não diminuíram. Tal comportamento pode ter sido con- 
sequência de fatores macroeconômicos, do mesmo modo que o aumento subsequente de $20 \%$, observado em 2009 , pode ter ocorrido como decorrência da política keynesiana de aumento dos gastos públicos para enfrentar a crise iniciada em 2008.

A análise da alocação dos recursos públicos para a PNSAN evidenciou a tendência crescente do aporte de recursos, uma ligeira descentralização com aumento da participação das transferências (de 78\% em 2004 para 81\% em 2010) e a concentração dos recursos em programas chaves (de 67,2\% para 91,6\%). Entre os programas com características de inserção econômica, dois se destacam: o programa Recursos Pesqueiros Sustentáveis e o de Agricultura Familiar, que teve grande importância em 2009, perdendo posição em 2010, mas ainda assim mantendo-se entre os cinco principais programas.

Porém, o principal programa da PNSAN, em termos de abrangência e em termos econômicos, é o PBF, um programa de alta capilaridade social pelo elevado número de beneficiários e por se tratar de uma transferência direta de renda. Em determinados municípios, sobretudo os mais pobres, a importância econômica do PBF é significativa, como ilustra uma visão panorâmica sobre a pequena economia da cidade de Bacabeira, no interior do Maranhão, cujo PIB per capita em 2009 era cerca de oito vezes menor que o da capital federal (16). Para esse município, o programa significou $15 \%$ do total de recursos recebidos do governo federal (9) em 2010.

Para Rocha (17) "um traço básico do desenho do BF é o fato de ele partir do pressuposto de que a transferência de renda é um mecanismo legítimo de política social no Brasil. Isto porque o país já alcançou um nível de renda per capita tal que torna a desigualdade o fator explicativo básico da persistência da pobreza. Neste sentido, pequenas transferências bem focalizadas têm forte impacto sobre a desigualdade de renda, apesar de representarem um dispêndio baixo em relação ao PIB do país, sendo, portanto, facilmente pagáveis" (p. 133).

Souza (18), comparando o PBF com os programas Chile Solidario, Red de Oportunidad (Panamá) e Oportunidades (México), conclui que o PBF tem um grau de focalização - isto é, a capacidade de atingir os sujeitos da ação, sem beneficiar pessoas não elegíveis nem excluir aquelas que deveriam ser beneficiadas - muito próximo desses programas, com exceção do primeiro decil de renda, em que a focalização é maior, pois $1 \%$ dos mais pobres congrega 3,5\% dos beneficiários do $\mathrm{PBF}$. Para esse autor, programas como o PBF, de transferências condicionais de renda, "marcam uma mudança na política social brasileira que passa a ser capaz de chegar aos mais pobres que antes eram pouco atingidos por não participarem do mercado formal de trabalho" (pp. 9-10). Contudo, o autor alerta que o custo fiscal de uma política social envolve, além dos valores das transferências diretas, os gastos relativos a execução e administração do programa. Em uma primeira aproximação, o pesquisador encontrou que para cada unidade monetária alocada ao PBF, $96 \%$ foi de benefícios recebidos pelas famílias. Apesar da elevada eficiência apresentada pelo programa, o autor sugere a existência de "peso morto" associado ao financiamento do programa, indicando que poderia haver aumento na distribuição de recursos às famílias pelo PBF.

Há um grande debate a respeito da redução da pobreza no Brasil nos últimos anos, destacando-se dois principais fatores: o crescimento econômico e a redução das desigualdades, sobretudo pelo crescimento maior da renda dos mais pobres relativamente à dos mais ricos. $\mathrm{A}$ renda dos $10 \%$ mais pobres aumentou em $8 \%$ em uma década, enquanto a dos $10 \%$ mais ricos subiu apenas $1,5 \%(19,20)$. Esses autores explicam esse aumento maior entre os de renda mais baixa principalmente pelo aumento real do salário mínimo e da escolaridade (19) e pela expansão de programas de transferência de renda (20), sobretudo o PBF.

Teoricamente, o aumento da renda poderia levar ao abandono do trabalho, pois o bem "lazer" passaria a ser uma opção a ser considerada. Nesse sentido, Souza (18) aponta estudos que indicam um impacto insignificante ou levemente negativo do PBF na oferta de trabalho por parte do trabalhador, apesar de citar outros em sentido contrário. Um estudo qualitativo, de 2008, com cinco mil titulares do cartão PBF, distribuídos nas cinco regiões brasileiras, em 229 municípios, identificou abandono do trabalho. O abandono, contudo, ocorreu apenas quando o trabalho era de extrema precariedade, assemelhado à escravidão (21).

Mais perto da questão nutricional em si, diversos estudos (22-25) e publicações do Ministério do Desenvolvimento Social e Combate à Fome, órgão responsável pela execução do $\mathrm{PBF}$, apontam que as famílias beneficiárias utilizam a maior parte do benefício (mais de 70\%) para aquisição de alimentos (26-28) e também com material escolar e medicamentos.

Assim, embora a concentração de recursos em um único programa de transferência de renda possa indicar, num primeiro momento, uma alocação concentrada dos recursos da PNSAN, a focalização desse programa, a forma como esses recursos estão sendo utilizados pela população e o efeito multiplicador nas pequenas economias são indicadores do acerto da política. Sabe-se, entretanto, que apenas a transferência de renda não garante uma alimentação saudável e adequada, sendo preciso que a política de nutrição e de alimentação evolua. A esse respeito, recente artigo de revisão (29) mostrou que ao mesmo tempo em que o PBF ampliou o acesso aos alimentos, contribuiu para o aumento do sobrepeso e da obesidade, na medida em que houve incremento do consumo de alimentos de elevada densidade energética. Os autores concluem sobre a necessidade de ações complementares, como a educação alimentar, para aumentar a efetividade do programa para a promoção da segurança alimentar e nutricional. Adicionalmente, a cesta de produtos e serviços oferecidos pelo poder público deve favorecer prioritariamente a autonomia econômica dos cidadãos e as condições estruturais da busca pela sobrevivência, fortalecendo inclusive as famílias para o enfrentamento das dificuldades inerentes às crises conjunturais.

Sob essa visão, o aumento do aporte de recursos para programas relacionados à agricultura familiar e à pesca sustentável mostra-se na direção correta. As ações para a agricultura familiar têm como objetivo o fortalecimento das atividades desenvolvidas pelo produtor familiar, de forma a integrá-lo à cadeia do agronegócio, proporcionando aumento de renda e agregando valor ao produto e à propriedade, mediante a modernização do sistema produtivo e a profissionalização e valorização dos produtores familiares. Associado ao programa de Aquisição de Alimentos, que garante a compra da produção a um preço justo, o apoio à agricultura familiar é um dos principais instrumentos de combate à pobreza rural. As ações do Programa de 
Recursos Pesqueiros Sustentáveis vão na mesma direção, pois promovem a sustentabilidade e a conservação das espécies, garantindo renda durante o período de restrição à pesca. $\mathrm{O}$ aporte para esse programa passou a ser expressivo a partir da transformação da Secretaria Especial de Aquicultura e Pesca da Presidência da República em Ministério da Pesca e Aquicultura, em meados de 2009. Observando-se a faixa entre o mínimo e o máximo de recursos alocados por programa, de 2004 a 2010, verifica-se que o Programa de Recursos Pesqueiros Sustentáveis foi o que mais sofreu variação, enquanto que o PBF e o Programa Nacional de Alimentação Escolar, que recebem mais recursos, foram os que menos variaram em termos proporcionais. Ainda assim, observou-se um aumento significativo de recursos para a alimentação escolar, em termos absolutos, que pode estar associado à inclusão de estudantes do ensino médio a partir de 2009 e ao reajuste do valor do repasse per capita aos alunos matriculados em 2010, bem como à ampliação do repasse para as creches e as escolas indígenas, quilombolas e de ensino integral nesse mesmo ano.

A PNSAN é complexa e os principais programas estão em sintonia com os dois primeiros eixos articuladores dessa política, a saber: o eixo de acesso aos alimentos (transferência de renda; alimentação escolar, bancos de alimentos; restaurantes populares) e o de fortalecimento da agricultura familiar. Outro vetor importante é aquele que trata da autonomia produtiva, geração de trabalho e aumento de renda, que estão diretamente relacionados ao mercado de trabalho, à formação educacional e à qualificação profissional. Há uma gama de programas e ações que já existem e foram identificados neste trabalho. Entretanto, como se observa na análise da alocação de recursos, os programas de autonomia produtiva receberam pequena parcela dos recursos da PNSAN. Parte dessas ações encontra-se nas principais metas do Plano Brasil Sem Miséria, que compõe o plano plurianual de 2012 a 2015, que irá nortear a atuação do governo federal para o período.

\section{REFERÊNCIAS}

1. Vasconcelos FAG. Combate à fome no Brasil: uma análise histórica de Vargas a Lula. Rev Nutr. 2005;18(4):439-57.

2. Pipitone MAP. Programa de Alimentação Escolar: um estudo sobre descentralização, escola e educadores [tese]. São Paulo: Universidade Estadual de Campinas; 1997.

3. Magalhães SG. Comissão Tripartite do Programa de Alimentação do Trabalhador: processo decisório [dissertação]. Rio de Janeiro: Escola Nacional de Saúde Pública; 2002.

4. Brasil. Lei 11346/2006. Disponível em: http:// www.planalto.gov.br/ccivil_03/_ato20042006/2006/lei/l11346.htm Acessado em janeiro de 2013.

5. Food Agriculture Organization of the United Nations (FAO). Voluntary guidelines to support the progressive realization of the right to adequate food in the context of national food security. FAO Report: Roma; 2005. Disponível em: ftp.fao.org/docrep/fao/009/y7937e/y 7937e00.pdf Acessado em janeiro de 2013.

6. Brasil, Conselho Nacional de Segurança Alimentar e Nutricional (CONSEA). Sistema Nacional de Segurança Alimentar e Nutricional. Disponível em: www4.planalto.gov.br/ consea / destaque/sistema-nacional-deseguranca-alimentar-e-nutricional Acessado em 10 de janeiro de 2012.

7. Lima DV, Castro RG. Contabilidade pública. São Paulo: Atlas; 2003.

8. Brasil, Ministério da Fazenda, Secretaria do Tesouro Nacional. Manual de despesa na- cional. Brasília, DF: Ministério da Fazenda/ Coordenação de Contabilidade Geral da Secretaria do Tesouro Nacional; 2008.

9. Brasil, Controladoria Geral da União (CGU). Portal da Transparência do Governo Federal. Disponível em: www.portaldatransparencia. gov.br Acessado em 1 de dezembro de 2011.

10. Braga V. Cultura alimentar: contribuições da antropologia da alimentação. Saude Rev. 2004;6(13):37-44

11. Silva JG, Belik W, Takagi M. Projeto Fome Zero. São Paulo: Instituto da Cidadania; 2001.

12. Brasil, Banco Central do Brasil. Demonstrações financeiras. Disponível em: www.bcb. gov.br/htms/inffina/be201112/dezembro 2011.pdf Acessado em 3 de junho de 2012.

13. Instituto Brasileiro de Geografia e Estatística (IBGE). Censo demográfico. Rio de Janeiro: IBGE; 2010. Disponível em: http://www. ibge.gov.br/home/estatistica/populacao/ censo2010/default.shtm Acessado em janeiro de 2013.

14. Instituto Brasileiro de Geografia e Estatística (IBGE). Censo agropecuário: resultados preliminares. Rio de Janeiro: IBGE; 2006. Disponível em: www.ibge.gov.br/home/estatistica/ economia/agropecuaria/censoagro/2006/ agropecuario.pdf Acessado em janeiro de 2013.

15. Custódio MB, Furquim NR, Santos GMM, Cyrillo DC. Segurança alimentar e nutricional e a construção de sua política: uma visão histórica. Rev SAN. 2011;18(1):1-10.
As novas ferramentas tecnológicas permitiram o presente estudo, que trouxe uma inovação na forma de observar a execução orçamentária, ao mesmo tempo abrangente, por considerar o todo, e focada, por considerar com relativa precisão apenas os recursos destinados às ações dos programas que realmente dialogam com a segurança alimentar e nutricional, desconsiderando os recursos dos programas gastos com processos administrativos ou burocráticos. Por outro lado, não foi possível avaliar a efetividade do gasto realizado. Sabe-se o montante que a União transferiu aos entes federados, mas não se sabe como foram gastos os recursos, nem pelos entes federados nem pela própria União. Ainda há muito a fazer para que o Brasil acabe com a fome que permeia parte da sociedade - mas a PNSAN é robusta, não apenas em termos institucionais, mas também em termos do montante de recursos aplicados.

Conflitos de interesse. Nada declarado pelos autores.
16. Instituto Brasileiro de Geografia e Estatística (IBGE). Cidades. Rio de Janeiro: IBGE; 2009. Disponível em: http://www.ibge.gov.br/ cidadesat/topwindow.htm?1? Acessado em janeiro de 2013

17. Rocha S. O programa Bolsa Família: evolução e efeitos sobre a pobreza. Econ Soc. 2011;20: 1(113-39).

18. Souza AP. Políticas de distribuição de renda no Brasil e o bolsa família. Em: Bacha EL, Schwartzman S. Brasil: a nova agenda social. São Paulo: Fundação Getúlio Vargas; 2011. P. 166-86.

19. Neri M. A nova classe média: o lado brilhante dos pobres. Rio de Janeiro: Centro de Políticas Sócias/Fundação Getúlio Vargas FGV/CPS; 2010.

20. Pochmann M. Nova classe média? O trabalho na base da pirâmide social brasileira. São Paulo: Boitempo; 2012.

21. Menezes F. Repercussões do Programa Bolsa Família na segurança alimentar e nutricional das famílias beneficiadas. Rio de Janeiro: IBASE; 2008.

22. The World Bank. Repositioning nutrition as central to development. A strategy for largescale action. Washington, DC: The International Bank for Reconstruction and Development/The World Bank; 2006. Disponível em: http://siteresources.worldbank.org/ NUTRITION / Resources / 281846 1131636806329/NutritionStrategy.pdf Acessado em janeiro de 2013. 
23. Brasil, Ministério da Saúde. Avaliação do programa Bolsa Alimentação. Brasília: Ministério da Saúde; 2005. (Série C. Projetos, Programas e Relatórios). Disponível em: http:/ / 189.28.128.100/nutricao/docs/geral/ av pba2.pdf Acessado em janeiro de 2013.

24. World Health Organization (WHO). Action on the social determinants of health: learning from previous experiences. Report. Genebra: WHO; 2005. Disponível em: http://www. who.int/social_determinants/resources/ action_sd.pdf Acessado em janeiro de 2013.

25. Attanasio O, Gómez LC, Heredia P, VeraHernández M. The short-term impact of a conditional cash subsidy on child health and nutrition in Colombia. The Institute for Fiscal Studies Report summary: Familias 03. Centre for the Evaluation of Development Policies; 2005. Disponível em: http:/ /lafabricacreativa. es/pruebas/impacto/sites/default/files/ informes evaluacion/170 THE\%20WORLD \%20BANK_nutricion\%20salud\%20Colombia. pdf Acessado em janeiro de 2013.

26. Burlandy L. Transferência condicionada de renda e segurança alimentar e nutricional. Cienc Saude Coletiva. 2007;12(6):1441-51.

27. Duarte GB, Sampaio B, Sampaio Y. Programa Bolsa Família: impacto das transferências sobre os gastos com alimentos em famílias rurais. Rev Econ Sociol Rural. 2009;47(4):903-18.
28. Instituto Brasileiro de Geografia e Estatística (IBGE). Pesquisa Nacional por Amostra de Domicílios. Rio de Janeiro: IBGE; 2009. http://www.ibge.gov.br/home/estatistica/ populacao/trabalhoerendimento/pnad2009/ pnad sintese 2009.pdf

29. Cotta RMM, Machado JC. Programa Bolsa Família e segurança alimentar e nutricional no Brasil: revisão crítica da literatura. Rev Panam Salud Publica. 2013:33(1):54-60.

Manuscrito recebido em 13 de fevereiro de 2012. Aceito em versão revisada em 5 de outubro de 2012.

ABSTRACT Objective. To describe the progression and distribution of federal funds for programs and activities that fall within the scope of the guidelines of the Brazilian National Policy on Food and Nutrition Security (PNSAN) in the period from 2004 to 2010 .

Food and nutrition security Methods. This descriptive study used data from the Transparency Website maintained by the Brazilian Public Sector Internal Control Office. Search results were exported to Excel spreadsheets. To determine the resources allocated to food security initiatives, a database was set up containing all actions developed by the federal government between 2004 and 2010. This database was reviewed and the actions that were not related to PNSAN were discarded. The annual amounts obtained were corrected by the Consumer Price Index and updated for the year 2010. Since actions are part of specific programs, the sum of the resources allocated for all the actions of a program amounted to the resources invested in the program as a whole. The programs were then prioritized according to the amount of resources received in 2010.

Results. Of the 5014 actions receiving federal funds in the study period, 814 were related to PNSAN (229 programs). There was growth in resources allocated for PNSAN programs, reaching US\$ 15 billion in 2010 (an 82\% increase over the previous year). The largest amount was invested in Bolsa Família, a cash transfer program. Ten programs received $90 \%$ of the funds, of which five were linked to food production processes.

Conclusions. The amount of resources invested in the PNSAN and in actions and programs that promote food and nutrition security is increasing in Brazil.

Key words Resource allocation; nutrition policy; food security; public policy; Brazil. 